UNIVERSIDADE DE SÃO PAULO

FACULDADE DE ECONOMIA, ADMINISTRAÇÃO E CONTABILIDADE DEPARTAMENTO DE ECONOMIA

PROGRAMA DE PÓS-GRADUAÇÃO EM ECONOMIA

A CONSTRUÇÃO DO OBJETO TEÓRICO DAS TEORIAS DO

DESENVOLVIMENTO ECONÔMICO

Danilo Freitas Ramalho da Silva

Orientador: Prof. Dr. Raul Cristóvão dos Santos

SÃO PAULO

2005 
Prof. Dr. Adolpho José Melfi Reitor da Universidade de São Paulo

Prpfa. Dra. Maria Tereza Leme Fleury Diretora da Faculdade de Economia, Administração e Contabilidade

Prof. Dr. Ricardo Abramovay Chefe do Departamento de Economia

Profa. Dra. Basilia Maria Batista Aguirre Coordenadora do Programa de Pós-Graduação em Economia 
DANILO FREITAS RAMALHO DA SILVA

\section{A CONSTRUÇÃO DO OBJETO TEÓRICO DAS TEORIAS DO DESENVOLVIMENTO ECONÔMICO}

Dissertação apresentada ao Departamento de Economia da Faculdade de Economia, Administração e Contabilidade da Universidade de São Paulo como requisito para a obtenção do título de Mestre em Economia.

Orientador: Prof. Dr. Raul Cristóvão dos Santos

\section{SÃO PAULO}

2005 


\section{FICHA CATALOGRÁFICA}

\section{Elaborada pela Seção de Processamento Técnico do SBD/FEA/USP}

Silva, Danilo Freitas Ramalho da

A construção do objeto teórico das teorias do desenvolvimento econômico / Danilo Freitas Ramalho da Silva. -- São Paulo, 2005. $96 \mathrm{p}$.

Dissertação (Mestrado) - Universidade de São Paulo, 2005 Bibliografia.

1. Economia 2. Desenvolvimento econômico 3. Economia - Teoria I. Universidade de São Paulo. Faculdade de Economia, Administração e Contabilidade II. Título.

$\mathrm{CDD}-330$ 